\title{
Penicillamine kinetics in normal subjects
}

\begin{abstract}
The kinetic characteristics of penicillamine are reported in four fasting subjects after four oral doses each. On later test days, two of the subjects received an additional single dose 30 min after a large breakfast. One subject originally included in the study had to drop out because of gastrointestinal disturbances following each of two single doses of penicillamine. The fasting plasma levels of penicillamine observed in this study displayed an unusual double peak in the plasma levels after single doses. Individual subjects had consistent plasma level patterns for each of the four single doses but there was marked intersubject variability in patterns and kinetic parameters. The half-life of unchanged penicillamine ranged from 1.66 to $3.15 \mathrm{hr}$ and the apparent plasma clearance ranged from 530 to $2300 \mathrm{ml} / \mathrm{min}$. The administration of penicillamine following a large breakfast caused a reduction in the area under the penicillamine plasma concentration-time curve corresponding to a decrease in the extent of absorption of unchanged penicillamine.
\end{abstract}

\author{
Richard F. Bergstrom, Ph.D.,*** Donald R. Kay, M.D.,*** \\ Thomas M. Harkcom, M.D., and John G. Wagner, Ph.D. Ann Arbor, Mich. \\ The Upjohn Center for Clinical Pharmacology, The College of Pharmacy, and The Rackham \\ Arthritis Research Unit, University of Michigan
}

Penicillamine has been in use for a number of years; in 1954 Walshe $^{26}$ first introduced it for the treatment of Wilson's disease. More recent studies of its therapeutic activities ${ }^{8,} 11$ have shown that penicillamine is effective in the treatment of rheumatoid arthritis, which has

\footnotetext{
Supported by grants 5P60-AM20557-02 and 2P60-AM20557-04 from the National Institutes of Health.

Received for publication April 6, 1981.

Accepted for publication May 22, 1981.

Reprint requests to: Dr. John G. Wagner, The Upjohn Center for Clinical Pharmacology, University of Michigan, Ann Arbor, MI 48109.

*1980-1981 American Foundation for Pharmaceutical Education Manufacturing and Industrial Pharmacy Fellow.

**Present address: Lilly Laboratory for Clinical Research, Eli Lilly \& Co., Wishard Memorial Hospital, Indianapolis, IN 46202.

***Present address: Division of Immunology and Rheumatology, Department of Medicine, University of Missouri, Columbia, MO 65201 .
}

greatly increased the use of, and research interest in, this compound. Throughout the several decades of the drug's use kinetic studies in man have been lacking, primarily because a specific and sensitive assay was not available. The development of suitable assay methodology has been hampered by the chemical similarity of the drug to a number of endogenous compounds, and a specific assay is essential for any drug to accurately define its kinetic characteristics. Many very sensitive analytic methodologies that have been developed for penicillamine (such as colorimetry, gas chromatography, and radioimmunoassay) are not useful for kinetic studies because of possible interference from endogenous compounds or penicillamine metabolites.

To avoid analytic problems previous kinetic studies of this drug have been done in ani- 


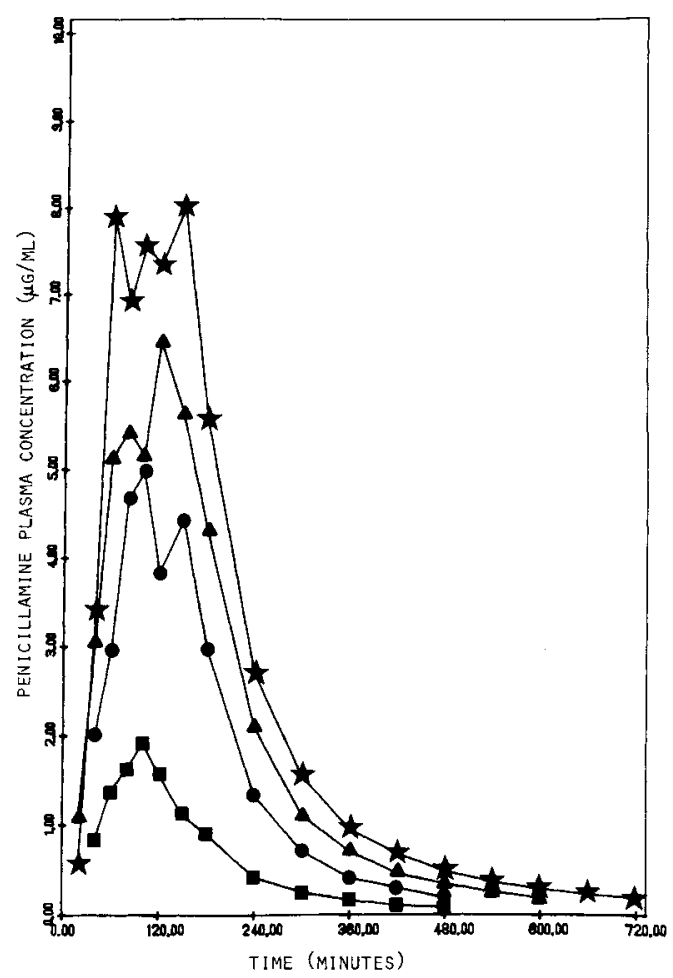

Fig. 1. Penicillamine plasma concentration levels after oral doses of $250(\mathbf{\bullet}), 500(\bullet), 750(\Delta)$, and $1,000 \mathrm{mg}(\star)$ of the drug to fasting patient P. B.

mals $^{12,13,15,18-20}$ and man $^{6,16,27}$ with radiolabeled penicillamine, but the results of these studies are inappropriate to describe the kinetics of unchanged drug; the levels measured represent both parent compound and metabolic products of penicillamine as described by Perrett. ${ }^{14}$

The development of a high-performance liquid chromatographic (HPLC) method for the determination of penicillamine ${ }^{21}$ has provided an assay method with the specificity and sensitivity necessary to conduct kinetic studies of the unchanged drug. We have modified this method and adapted it for our use. ${ }^{2}$

The study of unchanged penicillamine kinetics is further complicated by the rapid changes that have been shown to occur in the concentrations of the drug when it is placed in the presence of proteinaceous material (including whole blood, plasma, and albumin solutions). ${ }^{1}$ An accurate representation of the concentration of unchanged penicillamine in these biological fluids is obtained only by rapidly processing each

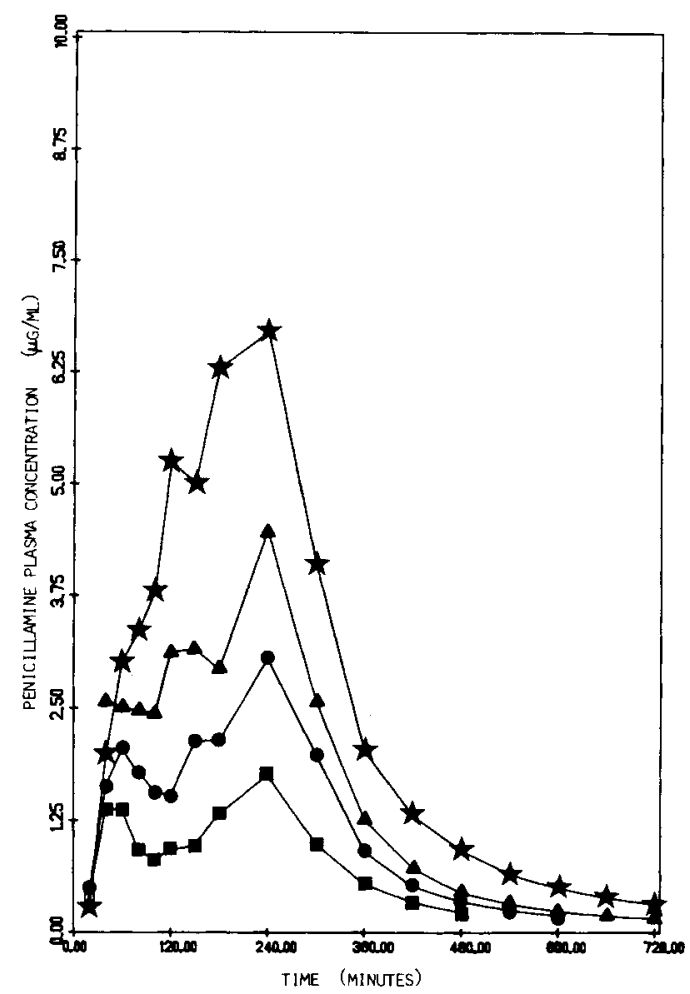

Fig. 2. Penicillamine plasma concentration levels after oral doses of $250(\bullet), 500(\bullet), 750(\bullet)$, and $1,000 \mathrm{mg}(\star)$ of the drug to fasting patient M. V.

sample $^{1}$ and so these procedures were used for the studies we report here.

We have reported on the kinetic characteristics of unchanged penicillamine in a female mongrel dog when the drug was injected as an intravenous bolus dose, as a constant-rate intravenous infusion, and in oral dose form. In this report we present the results of a kinetic study of penicillamine in five normal subjects. Four oral doses were given to each and the effect of food on the absorption efficiency of unchanged penicillamine were recorded.

\section{Methods}

Subjects. The kinetics of penicillamine were studied in five normal adult male and female subjects who were selected from respondents to an advertisement based on established criterion, namely, an assessment of the subject's availability and reliability, physical examination and medical history of the subject, and the results of hematologic, chemical, and urine analyses. The 


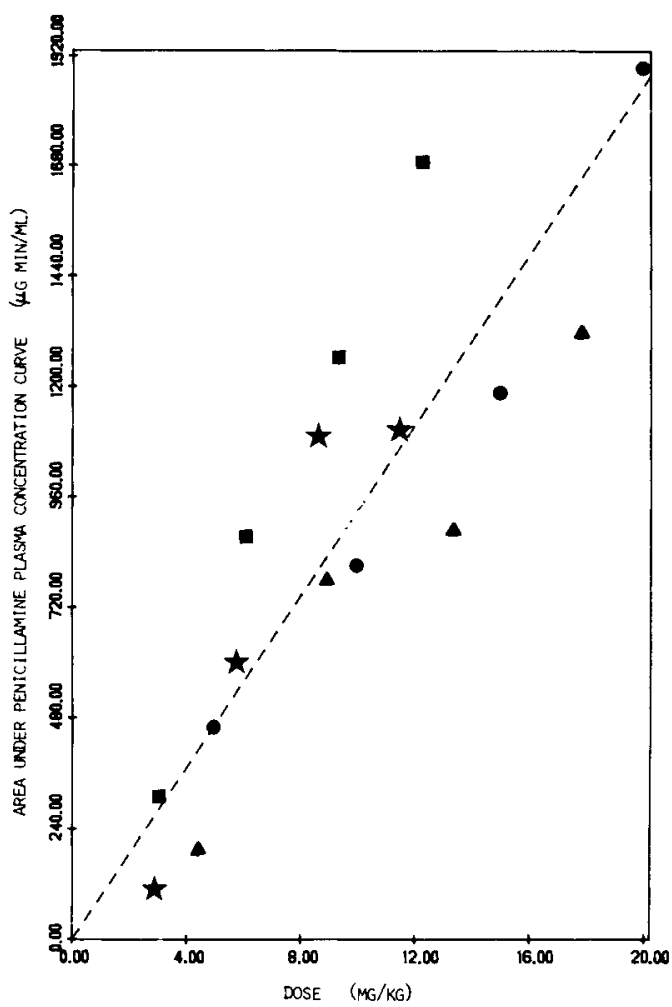

Fig. 3. Area under the penicillamine plasma concentration-time curve vs. drug dose after oral doses of 250,750 , and $1,000 \mathrm{mg}$ to the four fasting subjects

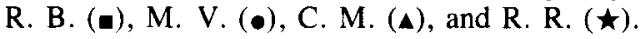

subjects were not accepted for participation if they were taking any other medications and they were instructed not to use any other medications for its duration. A differential white blood cell count, urine analyses, and a pregnancy test (for the women) were also completed before each dose of penicillamine on the day preceding the study date. The results of these tests were reviewed for signs of drug toxicity and abnormalities before the subjects were approved for the administration of the next dose of penicillamine. Individual test results that were outside the laboratory's normal range were repeated and these values were always within the normal range.

Kinetic study protocol. Each subject that completed the single-dose fasting study also received four sequentially larger doses of penicillamine $(250,500,750$, and $1,000 \mathrm{mg})$ at 2 -wk intervals. A fifth dose $(750 \mathrm{mg})$ was administered as an oral solution to one subject (R. B.) approximately a month and a half after the largest sequential dose. Several months after the completion of the fasting single-dose studies, subjects $R$. B. and C. M. also received additional single doses $(750 \mathrm{mg}) 30$ to $40 \mathrm{~min}$ after a large breakfast. Subject D. F. was dropped from the four-dose fasting study after two single doses because of nausea and headaches.

The best experimental design for a study constructed to test the effects of dose on the kinetics of a drug is the randomized crossover design. However, the sequentially incremented dose was chosen instead; if manifestations of drug toxicity or adverse reactions were detected in any of the subjects they would have occurred at the lowest possible dose.

The doses of penicillamine were taken at approximately $8 \mathrm{~A}$.M. after an overnight fast. No food or beverages (except water) were permitted after 9:30 P.M. on the day preceding the study. For the fasting studies no food or beverages (except water) were permitted until $4 \mathrm{hr}$ after the test dose of penicillamine. For the two doses taken after a large breakfast, the subjects were given the drug 30 to $40 \mathrm{~min}$ after two eggs, toast, orange juice, and coffee.

The doses were administered as multiples of 125-mg D-penicillamine capsules (Cuprimine) in all cases except the one oral solution dose given to subject $\mathbf{R}$. B. This dose was administered through a nasogastric tube as a $50 \mathrm{mg} / \mathrm{ml}$ solution of D-penicillamine. Each dose was taken with a minimum of $250 \mathrm{ml}$ of water.

Samples and assay procedure. Accurately timed blood samples were obtained from each subject at $0,20,40,60,80,120,150,180$, $240,300,360,420$, and $480 \mathrm{~min}$ after penicillamine. Additional hourly samples for up to 12 hr after drug were collected for the higher doses.

Blood samples were collected using a heparin lock that was inserted into the cephalic vein of each subject prior to the start of the study. Using a 3-ml syringe, approximately 1 to $3 \mathrm{ml}$ blood was drawn through the heparin lock and discarded to clear the cannula so it could be filled with fresh undiluted blood. A 5-ml blood sample was then drawn using a syringe that contained a small amount of heparin (approximately 50 to $100 \mu \mathrm{l}$ of $1,000 \mathrm{U} / \mathrm{ml}$ heparin). Between each blood sample the heparin lock 


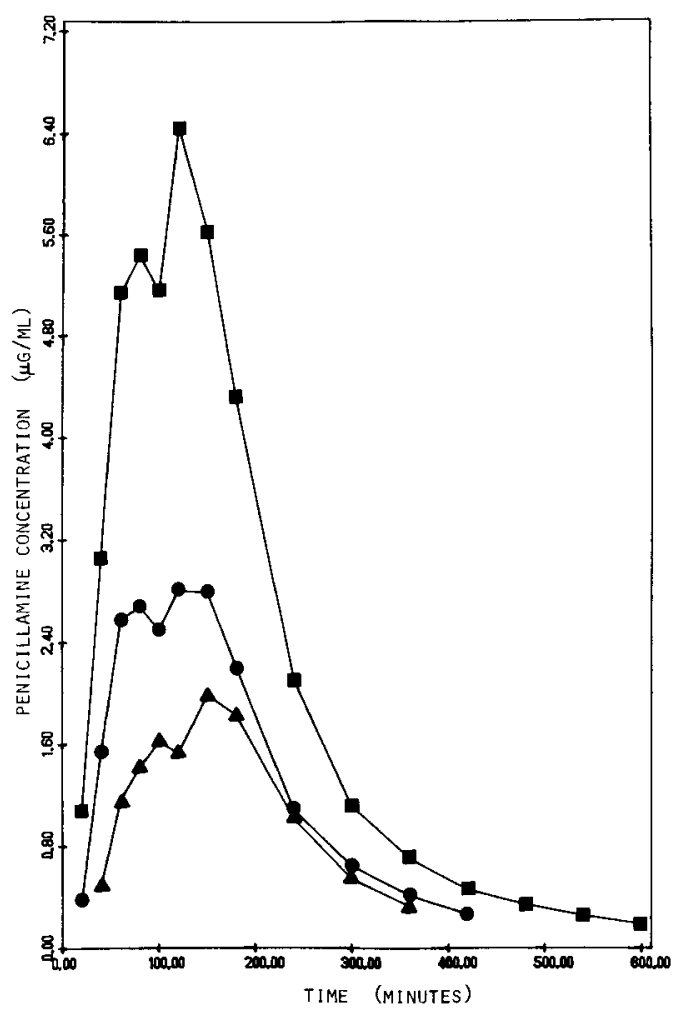

Fig. 4. Penicillamine plasma (₫), whole blood (•), and packed cell concentrations ( $\Delta$ ) after oral doses of $750 \mathrm{mg}$ (capsules) to fasting subject R. B.

was flushed and filled with 0.5 to $3 \mathrm{ml}$ sterile heparinized bacteriostatic sodium chloride injection, USP $(1,000 \mathrm{U}$ of heparin $/ 30 \mathrm{ml}$ with methyl and propyl paraben preservatives), to prevent the cannula from becoming clotted. Occasionally, however, the heparin locks were not functional and samples were obtained by direct venipuncture with 5 -ml heparinized syringes.

The blood samples were rapidly separated into plasma and packed cell components by centrifugation (Eppindorf microcentrifuge model 5412 , Brinkman Instruments) at $15,000 \mathrm{rpm}$ for 30 to $45 \mathrm{sec}$. The plasma was decanted and quickly processed by the methods outlined in previous publications $\mathrm{s}^{1,2}$ to produce the proteinfree, acidified plasma supernatant in which penicillamine is stable. The supernatant samples were immediately refrigerated and the penicillamine content of each sample was determined (within 1 to 5 days after collection of the samples) by an HPLC electrochemical method. ${ }^{3}$

For subject R. B. each blood sample was di-

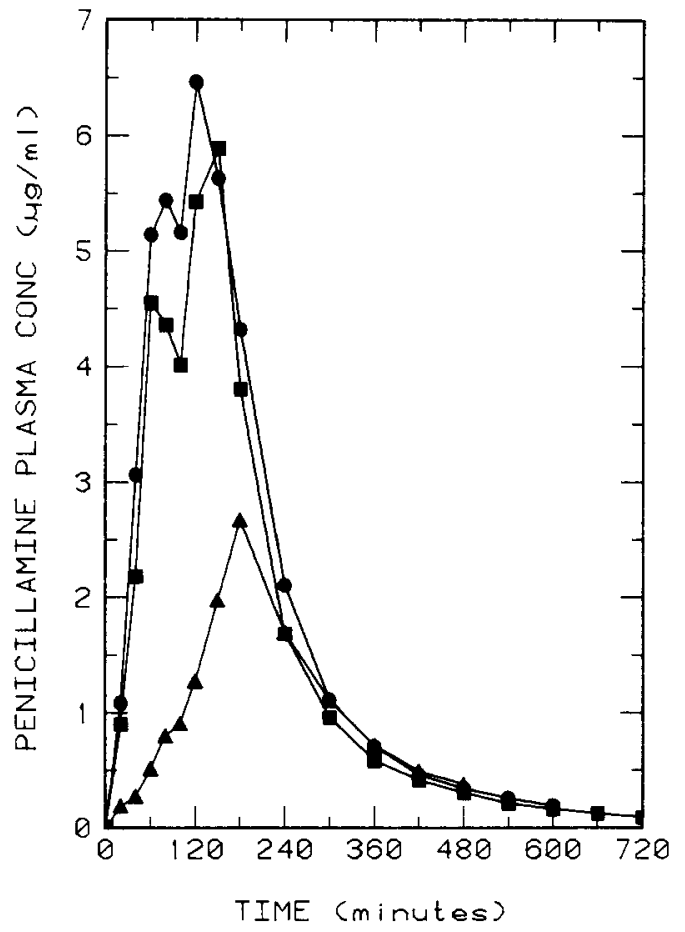

Fig. 5. Penicillamine plasma concentrations after 750 -mg doses as capsules ( $\square$ ) and in solution to fasting subjects (•) and as capsules after food (४).

vided into two parts, the first part being treated as a whole blood sample by completing a hemolysis and protein precipitation procedure as described previously. ${ }^{3}$ The second part of each sample was rapidly centrifuged into plasma and packed cell components as described above for the other subjects. Both of the plasma and packed cell fractions were processed as outlined in previous publications ${ }^{1}$ to produce stable supernatant samples. Therefore, in this subject alone, all three fractions (whole blood, plasma, and packed cell supernatants) were analyzed for their penicillamine content by the HPLC electrochemical method.

Total voided urine samples were collected for each subject over the intervals of 0 to 2,2 to 4 , 4 to 6,6 to 8,8 to 10 , and 10 to $12 \mathrm{hr}$ after the dose of penicillamine. In a few treatments, however, the 8- to 10 - or the 10 - to $12-\mathrm{hr}$ samples, or both, were lost or omitted. The volume of each sample was accurately determined and recorded. A suitable aliquot of urine was diluted 
Table I. Kinetic parameters calculated from the observed plasma concentrations of penicillamine in five normal subjects

\begin{tabular}{|c|c|c|c|c|c|}
\hline Subjects & $\begin{array}{l}\text { Dose } \\
(m g)\end{array}$ & $\begin{array}{c}A U C^{*} \\
(\mu g / \mathrm{min} / \mathrm{ml})\end{array}$ & $\begin{array}{c}\text { Elimination } \\
\text { rate } \\
\text { constant } \\
\left(h r^{-1}\right)\end{array}$ & $\begin{array}{c}\text { Half-life } \\
(h r)\end{array}$ & $\begin{array}{c}\text { Apparent plasma } \\
\text { clearance } \\
\text { Cl/FF* } \\
(\mathrm{ml} / \mathrm{min})\end{array}$ \\
\hline \multirow[t]{6}{*}{ R. B. } & 250 & $(4.3)$ & 0.357 & 1.94 & 808 \\
\hline & 500 & $(2.9)$ & 0.434 & 1.59 & 573 \\
\hline & 750 & 1260 & 0.295 & 2.35 & 593 \\
\hline & $7 \overline{750 \dagger}$ & 1089 & 0.287 & 2.41 & 689 \\
\hline & $750 \doteqdot$ & $559 \quad(12.5)$ & 0.418 & 1.66 & 1343 \\
\hline & 1000 & 1690 & 0.220 & 3.15 & 591 \\
\hline \multirow[t]{2}{*}{ D. F. } & 250 & $(5.0)$ & 0.505 & 1.37 & 1230 \\
\hline & 500 & $(3.5)$ & 0.443 & 1.56 & 1895 \\
\hline \multirow[t]{4}{*}{ M. V. } & 250 & $(6.5)$ & 0.443 & 1.56 & 542 \\
\hline & 500 & $(4.3)$ & 0.315 & 2.20 & 617 \\
\hline & 750 & 1190 & 0.223 & 3.11 & 632 \\
\hline & 1000 & 1890 & 0.232 & 2.98 & 528 \\
\hline \multirow[t]{5}{*}{ C. $\mathrm{M}$. } & 250 & $(5.6)$ & 0.469 & 1.48 & 1268 \\
\hline & 500 & $(3.4)$ & 0.308 & 2.25 & 642 \\
\hline & 750 & (2.1) & 0.388 & 1.78 & 846 \\
\hline & $750 \ddagger$ & $(9.7)$ & 0.397 & 1.75 & 2266 \\
\hline & 1000 & 1320 & 0.330 & 2.10 & 758 \\
\hline \multirow[t]{4}{*}{ R. R. } & 250 & $107 \quad(16.4)$ & 0.222 & 3.11 & 2343 \\
\hline & 500 & $(2.4)$ & 0.360 & 1.92 & 834 \\
\hline & 750 & 1090 & 0.312 & 2.22 & 689 \\
\hline & 1000 & $(2.2)$ & 0.318 & 2.18 & 906 \\
\hline
\end{tabular}

AUC was calculated from the trapezoidal rule and extrapolated to infinite time using the elimination rate constant and the last plasma concentration data point.

Elimination rate constant for the disappearance of penicillamine from plasma was calculated by linear regression of the log-linear terminal plasma concentration data.

$\mathrm{Cl} / \mathrm{FF}^{*}=$ Clearance divided by absorbed fraction times fraction undergoing first-pass metabolism.

Apparent plasma clearance was calculated from the ratio of the dose to the AUC.

*Data in parenthesis are percentages of total AUC that were extrapolated to infinite time.

$\nmid$ This oral dose was administered as a solution via nasogastric ube. All other doses were administered as capsules.

¥These oral doses were administered $30 \mathrm{~min}$ after a large breakfast. All other doses were taken in fasting state.

using $0.4 \mathrm{M}$ citric acid solution and the diluted, acidified urine specimens were immediately refrigerated. The penicillamine content of the urine samples was determined within 1 to 5 days by the HPLC electrochemical method.

Pharmacokinetic methods. The pharmacokinetic methods used are described in the footnotes to Tables I, II, and III.

\section{Results}

Penicillamine plasma levels. The plasma concentrations after the fasting oral administration of $250,500,750$, and $1,000 \mathrm{mg}$ of penicillamine as a capsule or in solution dosage form displayed atypical double peaks for the concentration-time profiles in all subjects studied. The fasting plasma concentrations for two of the subjects who received all four doses of penicillamine are shown in Figs. 1 and 2.

There were marked differences in the concentration-time profiles for the different subjects. The results shown in Figs. 1 and 2 are representative of the extremes observed for the subjects. As demonstrated in Figs. 1 and 2 , the fasting plasma concentration-time profiles within the same subject were remarkably similar, exhibiting the double peaks at approximately the same time after each dose of penicillamine.

The relationship of the area under the penicillamine concentration-time curve (AUC) to the dose of penicillamine for the four doses in subjects who completed the fasting protocol are shown in Fig. 3. The dotted line in this figure 
Table II. Kinetic parameters calculated from the observed urine levels of penicillamine for five normal subjects

\begin{tabular}{|c|c|c|c|c|}
\hline Subjects & $\begin{array}{l}\text { Dose } \\
(m g)\end{array}$ & $\begin{array}{c}\text { Amount } \\
\text { excreted } \\
(m g)\end{array}$ & \% of doset & $\begin{array}{c}\text { Renal clearance } \\
(\mathrm{ml} / \mathrm{min})\end{array}$ \\
\hline \multirow[t]{6}{*}{ R. B. } & 250 & 32.7 & 13.1 & 106 \\
\hline & 500 & 83.7 & 16.7 & 95.9 \\
\hline & 750 & 178 & 23.7 & 141 \\
\hline & 750 市 & 125 & 16.7 & 115 \\
\hline & $750 \S$ & 56.3 & 7.5 & 101 \\
\hline & 1,000 & 245 & 24.5 & 145 \\
\hline \multirow[t]{2}{*}{ D. F. } & 250 & 19.1 & 7.6 & 94.0 \\
\hline & 500 & 30.2 & 6.0 & 114 \\
\hline \multirow[t]{4}{*}{ M. V. } & 250 & 32.1 & 12.8 & 69.6 \\
\hline & 500 & 40.4 & 8.1 & 49.9 \\
\hline & 750 & 74.7 & 10.0 & 62.9 \\
\hline & 1,000 & 133 & 13.3 & 70.0 \\
\hline \multirow[t]{5}{*}{ C. M. } & 250 & 27.7 & 11.1 & 140 \\
\hline & 500 & 55.7 & 11.1 & 71.5 \\
\hline & 750 & 81.5 & 10.9 & 91.9 \\
\hline & $750 \S$ & 10.6 & 1.4 & 32.0 \\
\hline & 1,000 & 117 & 11.7 & 88.7 \\
\hline \multirow[t]{4}{*}{ R. R. } & 250 & 7.5 & 3.0 & 70.1 \\
\hline & 500 & 52.0 & 10.4 & 86.8 \\
\hline & 750 & 88.2 & 11.8 & 81.0 \\
\hline & 1,000 & 88.7 & 8.9 & 80.3 \\
\hline
\end{tabular}

Renal clearance was calculated from the ratio $A e \infty / \mathrm{AUC}_{0-\infty}$

*Amount in urine was extrapolated to infinite time using the method of Wagner and Ayres. ${ }^{25}$

†Percentage of dose that was ultimately excreted in urine.

$\ddagger$ Oral dose administered as a solution via nasogastric tube; others were as capsules.

$\S$ These oral doses were administered 30 min after a large breakfast; others were administered in fasting state.

was obtained by a linear regression of the data through the origin. The slope of the line is $0.0931 \mathrm{~min} \star \mathrm{kg} / \mathrm{ml}\left(+/-0.006, \mathrm{r}^{2}=0.735\right)$, which corresponds to an average plasma clearance of $10.7 \mathrm{ml} / \mathrm{min} / \mathrm{kg}$ or $749 \mathrm{ml} / \mathrm{min}$ for a $70-\mathrm{kg}$ man.

The plasma penicillamine concentrations for subject D. F., who developed nausea and headaches after each dose of penicillamine that he received, were significantly lower than the plasma levels of penicillamine in any of the other subjects. Although this subject experienced nausea, no episodes of emesis occurred during the 8 to $10 \mathrm{hr}$ of the study. The decreased penicillamine plasma levels for this subject, however, show that the gastric distress dramatically affected the plasma levels. The decreased plasma levels are probably due to malabsorption of the dose of penicillamine but the exact cause of the nausea and the poor absorption of penicillamine are not clear. The responses may be at- tributable to the usual adverse effects associated with use of the drug.

The plasma, whole blood, and packed cell concentration levels of penicillamine after the 750-mg dose administered (in capsules) to subject R. B. are shown in Fig. 4. The relationships between the concentration of the different components are consistent with the results observed in a female mongrel dog. ${ }^{3}$ The highest concentration of penicillamine for any component was that in the plasma compartment. Throughout the time course during which penicillamine blood levels were measured most of the unchanged drug remained in the extracellular (plasma) compartment. The low intracellular levels (relative to extracellular levels) are probably due to the intracellular presence of glutathione in red blood cells, which could readily oxidize the penicillamine transported inside these cells.

The ratios of the plasma concentrations to the whole blood concentrations of penicillamine 
Table III. Calculated dose and body weight invariant-Kinetic parameters for the human kinetic study of penicillamine in five normal subjects

\begin{tabular}{|c|c|c|c|c|}
\hline \multirow[b]{2}{*}{$\begin{array}{l}\text { Subjects' } \\
\text { age and sex }\end{array}$} & \multirow[b]{2}{*}{$\begin{array}{c}\text { Subjects' body } \\
\text { wt. (kg) }\end{array}$} & \multirow[b]{2}{*}{$\begin{array}{l}\text { Treatment re- } \\
\text { ceived (mg peni- } \\
\text { cillamine })^{*}\end{array}$} & \multirow[b]{2}{*}{$\begin{array}{c}\text { Dose } \\
(\mathrm{mg} / \mathrm{kg})\end{array}$} & \multirow{2}{*}{$\begin{array}{c}\text { Dose invarian } \\
\begin{array}{c}\text { AUC } \\
(\min / \mathrm{kg} / \mathrm{l})\end{array}\end{array}$} \\
\hline & & & & \\
\hline \multirow{7}{*}{$\begin{array}{l}\text { R. B. } \\
30 \quad(M)\end{array}$} & & & & \\
\hline & 81.6 & $250(f)$ & 3.06 & 101 \\
\hline & & $500(\mathrm{f})$ & 6.13 & 142 \\
\hline & & $750(\mathrm{f})$ & 9.18 & 137 \\
\hline & & 1,000 (f) & 12.2 & 138 \\
\hline & & $750(\mathrm{~s})$ & 9.18 & 119 \\
\hline & & 750 (b) & 9.18 & 60.9 \\
\hline \multirow{3}{*}{$\begin{array}{l}\text { D. F. } \\
37 \quad(\mathrm{M})\end{array}$} & & & & \\
\hline & 72.6 & 250 (f) & 3.44 & 59.0 \\
\hline & & $500(\mathrm{f})$ & 6.89 & 38.3 \\
\hline \multirow{5}{*}{$\begin{array}{l}\text { M. V. } \\
30 \quad(F)\end{array}$} & & & & \\
\hline & 50.3 & $250(\mathrm{f})$ & 4.96 & 92.9 \\
\hline & & $500(f)$ & 9.93 & 81.6 \\
\hline & & 750 (f) & 14.9 & 79.9 \\
\hline & & 1,000 (f) & 19.9 & 95.0 \\
\hline \multirow{7}{*}{$\begin{array}{l}\text { C. M. } \\
26 \quad(F)\end{array}$} & & & & \\
\hline & 56.2 & 250 (f) & 4.44 & 44.4 \\
\hline & & $500(\mathrm{f})$ & 8.89 & 87.6 \\
\hline & & 750 (f) & 13.3 & 66.7 \\
\hline & & $1,000(\mathrm{f})$ & 17.8 & 74.1 \\
\hline & & $750(\mathrm{~s})$ & 13.3 & 24.9 \\
\hline & & 750 (b) & & \\
\hline \multirow{5}{*}{$\begin{array}{l}\text { R. R. } \\
26 \quad(M)\end{array}$} & & & & \\
\hline & 87.5 & 250 (f) & 2.85 & 37.5 \\
\hline & & $500(f)$ & 5.71 & 105 \\
\hline & & 750 (f) & 8.57 & 127 \\
\hline & & $1,000(f)$ & 11.4 & 96.8 \\
\hline
\end{tabular}

Dose invariant AUC is the reciprocal of the body weight invariant apparent plasma clearance.

$*_{\mathrm{f}}=$ subject in fasting state; $\mathbf{s}=$ given in solution to subject in fasting state; $\mathrm{b}=$ given after large breakfast.

were not consistent throughout the time course of the measured levels. The ratios gradually decreased with time so that relatively more of the penicillamine was found intracellularly in the later samples than in the early samples. However, the summation of the concentrations in the plasma and packed cells components when corrected for the hematocrit were (within analytic error) always equal to the concentration found in the whole blood. Since the whole blood levels of penicillamine reflect the concentration in more than one compartment, plasma levels of penicillamine should be utilized for the study of the penicillamine kinetics. The use of the plasma levels has an additional advantage because the plasma concentrations are higher than those found in the whole blood or packed cells. Thus, analytic determination of penicillamine in plasma is easier and the plasma levels can be observed for a longer period of time before the concentration falls below the limits of detection of the analytic methodology.

Fig. 5 shows a comparison of the plasma levels of penicillamine for subject $R$. B. after a 750 -mg dose in capsules (fasting and after food) and as an oral solution $(50 \mathrm{mg} / \mathrm{ml})$ through a nasogastric tube). Unfortunately, difficulty was encountered during the administration of the oral solution when the connection between the nasogastric tube and the syringe containing the dose to be administered leaked. The dose was therefore less than $750 \mathrm{mg}$. Because the exact 


\begin{tabular}{|c|c|c|}
\hline & \multicolumn{2}{|c|}{ Body wt. invariant } \\
\hline $\begin{array}{l}\text { Amount ex- } \\
\text { creted in urine } \\
(\mathrm{mg} / \mathrm{kg})\end{array}$ & $\begin{array}{c}\text { Apparent } \\
\text { plasma } \\
\text { clearance } \\
(\mathrm{ml} / \mathrm{min} / \mathrm{kg})\end{array}$ & $\begin{array}{c}\text { Renal } \\
\text { clearance } \\
(\mathrm{ml} / \mathrm{min} / \mathrm{kg})\end{array}$ \\
\hline
\end{tabular}

\begin{tabular}{rrl}
10.7 & 9.9 & 1.30 \\
13.7 & 7.0 & 1.17 \\
19.4 & 7.3 & 1.73 \\
20.1 & 7.2 & 1.78 \\
13.6 & 8.4 & 1.41 \\
6.1 & 16.5 & 1.23 \\
& & \\
5.55 & 16.9 & 1.29 \\
4.38 & 26.1 & 1.57 \\
& & \\
6.47 & 10.8 & 1.38 \\
4.07 & 12.3 & 0.991 \\
5.01 & 12.6 & 1.25 \\
6.68 & 10.5 & 1.39 \\
& & \\
6.24 & 22.5 & 2.49 \\
6.26 & 11.4 & 1.27 \\
6.13 & 15.0 & 1.63 \\
6.57 & 13.5 & 1.58 \\
0.80 & 40.3 & 0.57 \\
& & \\
2.63 & & \\
9.11 & 26.8 & 0.801 \\
10.3 & 9.53 & 0.991 \\
7.78 & 7.87 & 0.925 \\
\hline & 10.3 & 0.917 \\
\hline
\end{tabular}

magnitude of this error is not known a comparison of the solution dose AUC to the AUCs of other doses is not valid.

The relative shapes of the plasma concentration-time profiles for these doses can, however, be compared. Both the oral solution dose and the capsule dose taken in the fasting state display double peaks at approximately the same time after dose. These results suggest that the double peaks observed are not merely due to the administration of a number of capsules.

The plasma levels of penicillamine resulting from the dose after a large breakfast showed a great reduction in the AUC and a disappearance of the double peaks. These observations were consistent in both subjects to whom doses were given after a large breakfast.

Table I lists the kinetic parameters that were calculated based on the observed penicillamine plasma concentration data for the five subjects. The large apparent plasma clearances reported for subject D. F. are a reflection of the subject's poor absorption of the drug. Similarly, the large apparent plasma clearances reported for the doses given with food to subjects R. B. and C. M. are due to decreased absorption of unchanged penicillamine when it is taken after food.

Urinary excretion of penicillamine. The intrasubject variability in the plasma data was also observed in the urinary elimination of penicillamine. Table II lists the kinetic parameters for penicillamine that were calculated from the urine data for the five subjects. The percentages of the dose that were excreted unchanged ranged from $3 \%$ to $25 \%$ and the renal clearance of penicillamine ranged from 50 to $145 \mathrm{ml} / \mathrm{min}$.

The renal clearance of penicillamine reported in Table II was estimated as a ratio of the amount excreted in infinite time to the AUC from zero to infinite time. Excretion rates in the intervals 0 to 2,2 to 4,4 to 6,6 to 8,8 to 10 , and 10 to $12 \mathrm{hr}$ were also calculated and related to the plasma concentrations at the midpoints of the urinary excretion intervals, namely, $1,3,5$, 7,9 , and $11 \mathrm{hr}$. The data were pooled over dose for each subject and were plotted. The plots were linear for subjects R. B., D. F., M. U., and R. R., while the data for subject C. M. exhibited some curvature at the low plasma concentrations. The plot slopes are also estimates of the renal clearance. These renal clearances $(104,89.2,64$, and $80.2 \mathrm{ml} / \mathrm{min}$ for subjects R. B., D. F., M. U., and R. R., respectively) were of the same order as those reported in Table II. Their linearity suggests that penicillamine obeys a linear kinetic system and that it cannot be highly and tightly bound to plasma proteins.

After two doses subject D. F. excreted less penicillamine in the urine than any of the other subjects at comparable doses. The renal excretion of penicillamine was also decreased in subjects R. B. and C. M. when the doses were taken with food. These reductions in the amount of drug excreted in are another reflection of the decreased absorption in these subjects.

Invariant parameter analysis. To analyze 
the effect of dose and body weight on the kinetic parameters of penicillamine, the parameters were calculated as dose invariant or body weight invariant. The results of these calculations as well as the subject's age, sex, and body weight are shown in Table III.

For the four fasting subjects the invariant parameters were analyzed by a two-factor ANOVA for the effect of dose and subject. The dose invariant AUC was not different between doses $(P<0.05)$ but was different between subjects $(P>0.01)$. The dose invariant amount of penicillamine excreted in the urine and the body weight invariant renal clearance were also not different between doses $(\mathrm{P}<0.1)$ but were different between subjects $(P>0.025)$. The body weight invariant plasma clearance was not different $(P<0.075)$ for either dose or subject.

\section{Discussion}

The atypical plasma concentration-time patterns in these studies are unusual. However, double peaks in the blood level curves have been observed for other drugs, including cimetidine, ${ }^{4,} 7,9,22-24$ phenytoin, ${ }^{10,} 17$ and phenolphthalein. ${ }^{5}$ The occurrence of double peaks in our study of penicillamine does not appear to be merely due to the number of capsules taken because a double peak was also observed for the subject given an oral solution.

Other explanations for the occurrence of double peaks in the blood levels of drugs include cyclic processes such as enterohepatic recirculation. In these cases, however, the double peak should be apparent regardless of the route of administration. The curves representing intravenous penicillamine to a female mongrel $\operatorname{dog}^{3}$ did not exhibit double peaks, but the oral penicillamine in both man and dog did. ${ }^{3}$ These results suggest that the occurrence of double peaks is linked to oral administration. (They were not evident, however, when the oral dose of penicillamine was administered after food.)

Similar results have been described for cimetidine. ${ }^{24}$ When this drug is administered intravenously, intramuscularly, or orally with food, double peaks are not observed but they are evident after oral drug (without food). The causes of the double peaks observed for penicillamine and cimetidine have not been determined, but these unusual concentration-time profiles may be due to gastrointestinal transit time or an "absorption window" effect. Vens Pedersen and Miller ${ }^{23,}{ }^{24}$ theorized that the effects are due to a cyclic process that is interrupted by the presence of food and insignificant for the parenteral routes of administration.

Our results have shown a significant decrease in the relative bioavailability of penicillamine when taken after a meal; bioavailability after food was only $44.4 \%$ and $37.3 \%$ of that when the subjects fasted. However, the apparent decrease in absorption when the dose is taken after food must be interpreted with caution. Previous reports in our laboratory ${ }^{1}$ have shown that penicillamine is readily oxidized (in vitro) to penicillamine disulfide when it is placed in the presence of proteinaceous material such as albumin. This oxidative process may also occur in the gastrointestinal tract when proteinaceous food materials are present (as egg albumin may have been in these studies). Since the analytic methodology used for the determination of penicillamine is specific for only the reduced form of penicillamine, the "complete" availability of the dose of (including both the reduced form and the disulfide or oxidized form) may be unchanged. A determination of both penicillamine and penicillamine disulfide was not obtained in this study.

The therapeutically active modality for penicillamine in the treatment of rheumatoid arthritis is still unknown; so the reduction in the absorption of the reduced form of penicillamine demonstrated by these studies may be of therapeutic importance. Other studies are necessary to prove this relationship.

The large intrasubject variability in the kinetic parameters of penicillamine is of interest in light of the adverse effects in some individuals receiving long-term administration. A correlation of kinetic parameters such as renal clearance and dose invariant AUC with the occurrence of adverse effects such as proteinuria may be useful in elucidating the cause of the effects or in predicting if they will occur.

\section{References}

1. Bergstrom RF, Kay DR, Wagner JG: The in vitro loss of penicillamine in plasma, albumin 
solutions, and whole blood: Implications for pharmacokinetic studies of penicillamine. Life Sci 27:189-198, 1980.

2. Bergstrom RF, Kay DR, Wagner JG: High performance liquid chromatographic determination of penicillamine in whole blood, plasma, and urine. J Chromatogr 222:445-452, 1981

3. Bergstrom RF, Kay DR, Wagner JG: The pharmacokinetics of penicillamine in a female mongrel dog. J Pharmacokinet Biopharm (In press.)

4. Bodemar G, Norlander B, Fransson L, Walan A: The interference of a meal and antacids on cimetidine absorption in patients with peptic ulcer disease. Scand J Gastroenterol 12:12, 1977.

5. Colburn WA, Hirom PC, Parker RJ, Milburn P: A pharmacokinetic model for enertohepatic recirculation in the rat: Phenolphthalein, a model drug. Drug Metab Dispos 7:100-102, 1979.

6. Gibbs K, Walshe JM: Studies with S-labeled DL-penicillamine in patients with Wilson's disease. Q J Med 84:823-827, 1971 .

7. Grahnen A, von Bahr C, Lindstrom R, Rosen A: Bioavailability and pharmacokinetics of cimetidine. Eur J Clin Pharmacol 16:335-340, 1979.

8. Jaffe IA: The effect of penicillamine on laboratory parameters in rheumatoid arthritis. Arthritis Rheum 8:1064-1079, 1965.

9. Larsson R, Bodemar G, Norlander B: Oral absorption of cimetidine and its clearance in patients with renal failure. Eur J Clin Pharmacol 15:153-157, 1979.

10. Melander A, Brante G, Johansson O, Lindberg $T$, Wahlin-Boll E: Influence of food on the $a b-$ sorption of phenytoin in man. Eur $\mathrm{J}$ Clin Pharmacol 15:269-274, 1979.

11. Multicentre Trial Group: Controlled trial of $\mathrm{D}-(-)$-penicillamine in severe rheumatoid arthritis. Lancet 1:275, 1973.

12. Patzsche K, Wegner LA: Pharmacokinetic studies after application of C-D-penicillamine to rats. Arzneimitteforsch 27:1152-1158, 1977.

13. Patzschke K, Wegner L, Kaller H, Horster FA: Pharmakokinetische untersuchunger nach oraler applikation von radioaktiv markiertem D-penicillamin an probanden. Z Rheumatol 36:96-105, 1977.

14. Perrett D: An outline of D-penicillamine metabolism. Proc R Soc Med 70(suppl. 2):61-64, 1977.
15. Planas-Bohne F: Pharmacokinetics of C-labeled penicillamine. Arzneimittelforsch 22: 1426-1433, 1972

16. Polis E, Planas-Bohne F: Compartmental study on the pharmacokinetics of D-penicillamine. Biophysik 10:321-336, 1973.

17. Robinson JP, Morris BA, Aherne GW, Marks $\mathrm{V}$ : Pharmacokinetics of a single dose of phenytoin in man measured by radioimmunoassay. $\mathrm{Br}$ J Clin Pharmacol 2:345-349, 1975.

18. Ruiz-Torres A: On the pharmacokinetics and metabolism of D- and L-penicillamine (1st communication): Blood levels, transport. Arzneimittelforsch. 24:914-917, 1974.

19. Ruiz-Torres A: On the pharmacokinetics and metabolism of D- and L-penicillamine ( 2 nd communication): Distribution of D-and L-penicillamine in the rat organ after oral administration. Arzneimittelforsch 24: 1043-1046, 1974.

20. Ruiz-Torres A, Kurten I: On pharmacokinetics and metabolism of D- and L-penicillamine (3rd communication): Absorption, excretion, and metabolism. Arzneimittelforsch 24:1258-1261, 1974.

21. Saetre R, Rabenstein DL: Determination of penicillamine in blood and urine by high performance liquid chromatography. Anal Chem 50:276-280, 1978 .

22. Somogyi A, Rohner HG, Gugler R: Pharmacokinetics and bioavailability of cimetidine in gastric and duodenal ulcer patients. Clin Pharmacokinet 5:84-94, 1980

23. Veng Pedersen P: Pharmacokinetic analysis by linear system approach I: Cimetidine bioavailability and second peak phenomenon. J Pharm Sci 70:32-38, 1981 .

24. Veng Pedersen P, Miller R: Pharmacokinetics and bioavailability of cimetidine in humans. J Pharm Sci 69:394-398, 1980.

25. Wagner JG, Ayres JW: Bioavailability assessment: Method to estimate total area (AUC O-x) and total amount excreted $(\mathrm{Ae} x)$ and importance of blood and urine sampling scheme with application to digoxin. J Pharmacokinet Biopharm 5:533-557, 1977

26. Walshe JM: Penicillamine, a new oral therapy for Wilson's disease. Am J Med 21:487-495.

27. Wei P, Sass-Kortsak A: Urinary excretion and renal clearances of D-penicillamine in humans and the dog. Gasteroenterology 58:228, 1970. 